\title{
Characteristics of Muscle Activity in the Lower Extremity during Stepping over Various Obstacle
}

\author{
Han-Suk Lee, PhD, PT, $\mathrm{DMT}^{\dagger} \cdot$ Seung-Beom Hong $\cdot$ Ha-Nul Chin • Ju-Li Choi $\cdot$ \\ Hee-Chang Seon, PT, BS ${ }^{1} \cdot$ Duk-Young Jeong, PhD $^{2}$ \\ Department of Physical Therapy, Eulji University \\ ${ }^{1}$ Department of Physical Therapy, Graduate School, Eulji University \\ ${ }^{2}$ Seongnam Senior Complex
}

Received: October 24, 2019 / Revised: October 24, 2019 / Accepted: November 5, 2019

(c) 2019 J Korean Soc Phys Med

\section{| Abstract |}

PURPOSE: This study examined the muscle activity while stepping over obstacles with various heights and widths to provide basic data for training and preventing falls.

METHODS: Fifteen normal young adults (seven males and eight females) were recruited. The participants walked on a $5 \mathrm{~m}$ walkway with six obstacles. The heights of obstacles were $0 \%, 10 \%$, and $40 \%$ of the subject's leg length, and the width of the obstacles was $7 \mathrm{~cm}$ and $14 \mathrm{~cm}$. The participants traversed the course twice per obstacle. The muscle activities of the soleus, tibialis anterior (TA), vastus medialis (VM), and vastus lateralis (VL) were measured using surface electromyography. A Mann-Whitney test and KruskalWallis test were used to examine the differences between obstacles.

†Corresponding Author : Han-Suk Lee

leehansuk21@hanmail.net, https://orcid.org/0000-0002-9336-0894

This is an Open Access article distributed under the terms of the Creative Commons Attribution Non-Commercial License (http://creativecommons.org/licenses/by-nc/3.0) which permits unrestricted non-commercial use, distribution, and reproduction in any medium, provided the original work is properly cited.
RESULTS: The muscle activities of the VL and the soleus of the stance leg and lead leg after crossing over the obstacles increased with increasing width, and there were significant differences in muscle activities between obstacle width $(p<.05)$ except for the muscle activity of TA of the stance leg after crossing over the obstacles. A significant difference in muscle activities was observed according to the height of the obstacles with $14 \mathrm{~cm}(\mathrm{p}<.05)$ except for the muscle activity of the VL, soleus of the leading leg, and TA of the stance leg CONCLUSION: The role of the VL and Soleus increased with increasing obstacle width, and the overall muscle activities of the lower extremities increased with increasing obstacle height. These results can be used to suggest a program to prevent falls.

Key Words: Muscle activity, Electromyography, Walking

\section{Introduction}

Various obstacles, such as dirt roads, sidewalk blocks, sand, boulder paths, and stairs, are encountered in daily life. Falls can occur while stepping over these obstacles [1]. Proper weight shift, strength, and good balance are 
necessary to traverse an obstacle without falling.

Some studies have examined the gait characteristics of step-over obstacles to prevent falls in daily life [1-3]. Krell and Patla [4] predicted the interval between obstacles and feet and reported that the strength of the lower extremity is necessary to pass safely over obstacles. According to Park [5], the muscle activities of the rectus femoris, semitendinosus, tibialis anterior (TA), and gastrocnemius increased with increasing obstacle height. Patients with disease, however, have more difficulty in lifting their feet [6].

As the obstacle height increased, more muscle force and coordination are needed to prevent falls in both healthy people and those with disease [1-6]. Therefore, it is necessary to study the neurophysiological mechanism that analyzes muscle activity while stepping over various types of obstacles. On the other hand, most studies focused on strategies by varying the obstacle height and training programs, but few studies have examined the effects of the obstacle width.

One of the major factors affecting falls during walking is the type of obstacle. In particular, falls while passing over obstacles, such as platforms and bathtubs, can frequently occur in daily life. Approximately $10 \%$ of the step length $(14 \mathrm{~cm})$ is the distance where accidents can occur at subway platforms. Accordingly, $5 \%$ of the step length $(7 \mathrm{~cm})$ is the distance suggested by the Seoul Metropolitan Rapid Transit Corporation for safe walking on subway platforms. In addition, according to Houser et al. [7], the $10 \%$ height of the leg length $(8-10 \mathrm{~cm})$ means the height of a doorsill and $40 \%(36-40 \mathrm{~cm})$ of the leg length is the height of a bathtub. Individuals frequently need to pass over obstacles like these platforms, doorsills, and bathtubs every day, and it is important to prevent falls in this environment. Therefore, it is necessary to determine the characteristics of walking while stepping over these obstacles to prevent tripping and falls. Therefore, this study examined muscle activity while stepping over obstacles of various heights and widths to provide basic data to train
Table 1. General Characteristics of the Participants

\begin{tabular}{cc}
\hline & Mean \pm Standard Deviation \\
\hline Age (year) & $24 \pm 1.9$ \\
Height $(\mathrm{cm})$ & $169.2 \pm 8.2$ \\
Weight $(\mathrm{kg})$ & $61 \pm 9.3$ \\
Leg length $(\mathrm{cm})$ & $90.9 \pm 6.8$ \\
\hline
\end{tabular}

and prevent falls.

\section{Methods}

\section{Participants}

This study was conducted on fifteen normal young adults (seven males and eight females) who were agreed to participate in this pilot study (IRB:EU18-72). The inclusion criteria were those who had no history of neurological and musculoskeletal disorders within the last three months or who had no pain while walking. Table 1 lists the general characteristics of the participants.

\section{Equipment}

\section{1) Type of obstacle}

Six obstacles were used in this study. The heights were $0 \%, 10 \%$, and $40 \%$ of the subject's leg length, and the widths were $7 \mathrm{~cm}$ and $14 \mathrm{~cm}$ (Fig. 1).

\section{2) Equipment of measurement}

The muscle activity of the soleus, TA, vastus medialis (VM), and vastus lateralis (VL) was measured using surface electromyography (Trigno wireless EMG, Delsys, Boston, 2014). The site of attachment was based on the location suggested by Criswell et al. [8]. The site of the soleus is on a half-point at the connected line of the lateral malleolus and lateral femoral epicondyle. The TA can be found on the top third point at the line connecting the medial malleolus and fibular head. The site of the VL is 

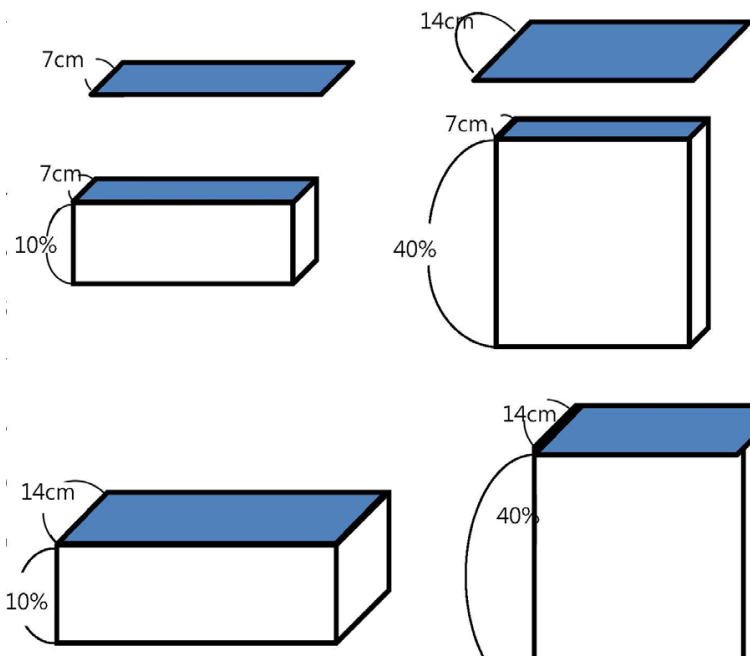

Fig. 1. Type of obstacle.
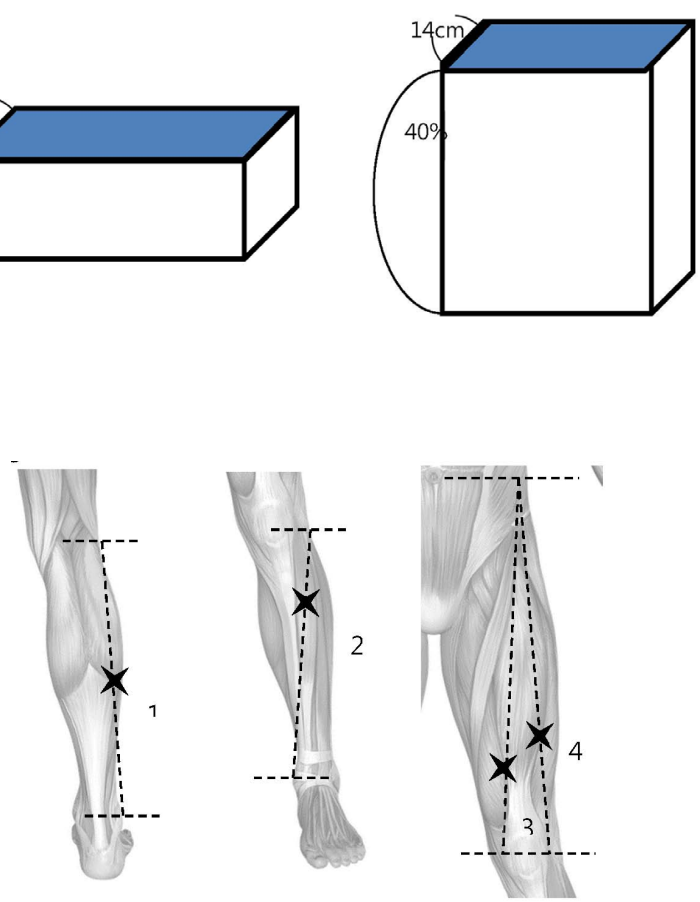

Fig. 2. Site of EMG

1: Soleus, 2: Tibialis Anterior, 3: Vastus Medialis, 4: Vastus Lateralis.

on the bottom third point at the line connected to the anterior superior iliac spine (ASIS) and the lateral aspect of the patella. The site of the VM is on the bottom one-fifth point at the line connecting the ASIS and medial collateral ligament.

The site of the VL is on the third bottom point at the line connecting the ASIS and lateral aspect of the patella [8] (Fig. 2). A 3D motion analysis system (VICON Motion System, UK, 2013) was used to find the position of the lower extremity while the participants crossed over the obstacles. Markers were attached to the center of the front of the shoes and top of the obstacle to distinguish the location of the obstacles, trail leg, and lead leg

\section{Experimental procedure}

The total length of the walkway was $5 \mathrm{~m}$, and the obstacle was located at $3 \mathrm{~m}$. The EMG values were collected after $1 \mathrm{~m}$ from the starting point. First, the subject walked $5 \mathrm{~m}$ at a comfortable speed to use a reference value after two practice walks. After the first reference walk, the subject crossed over six obstacles with their right foot. The subject walked twice over each obstacle after the tester placed 
Table 2. Comparison of the Muscle Activity Analysis According to the Obstacle Width (Median Value)

\begin{tabular}{ccccc}
\hline \multirow{2}{*}{ Event } & Muscle & \multicolumn{3}{c}{ Width of obstacle } \\
\cline { 3 - 5 } & & $7 \mathrm{~cm}$ & $14 \mathrm{~cm}$ & $\mathrm{p}$ \\
\cline { 2 - 5 } Stance Leg & VM & 13.73 & 17.27 & .285 \\
& VL & 15.27 & 15.73 & .902 \\
& TA & 15.00 & 16.00 & .775 \\
& Soleus & 15.27 & 15.73 & .902 \\
\hline \multirow{3}{*}{ Lead Leg } & VM & 14.07 & 16.93 & $.389^{\mathrm{b}}$ \\
& VL & 12.33 & 18.67 & .050 \\
& TA & 16.60 & 14.40 & .512 \\
& Soleus & 12.33 & 18.67 & .050 \\
\hline \multirow{3}{*}{ Stance Leg After Crossing Over Obstacle } & VM & 12.87 & 18.13 & $.106^{\mathrm{b}}$ \\
& VL & 11.60 & 19.40 & $.015^{*}$ \\
& TA & 18.20 & 12.80 & .098 \\
& Soleus & 11.60 & 19.40 & $.015^{*}$ \\
\hline \multirow{2}{*}{ Trailing Leg } & VM & 13.67 & 17.33 & $.267^{\mathrm{b}}$ \\
& VL & 13.93 & 17.07 & .345 \\
& TA & 17.40 & 13.60 & .250 \\
& Soleus & 15.40 & 15.60 & .967 \\
\hline
\end{tabular}

VM: Vastus Medialis, VL: Vastus Lateralis, TA: Tibialis Anterior, ${ }^{*} \mathrm{P}<.05$

a,b,c: Post hoc analysis using Bonferroni's method $(\alpha=.017)$

the obstacles randomly, and a three-minute rest was allowed after crossing over the obstacle.

\section{Data analysis}

The EMG signal was processed with bandpass filtering of 20 to $500 \mathrm{~Hz}$ and smoothing, and the root mean square (RMS) was determined using Excel (Math: Fig. 2). The mean EMG value after twice stepping over an obstacle was normalized using the EMG value of the reference walk:

$$
x_{\operatorname{mas}}=\sqrt{\frac{1}{n}\left(x_{1}^{2}+x_{2}^{2}+\cdots+x_{n}^{2}\right)} .
$$

\section{Statistical processing}

Descriptive statistics were used to analyze the general characteristics, and the muscle activities were analyzed using a Mann-Whitney test. A Kruskal-Wallis test was used to examine the difference according to the height of the obstacle. All data were analyzed using SPSS 20.0(IBM, Korea). The statistical significance level was set to $a=.05$. Post hoc analysis was performed using Bonferroni's method $(a=.017)$

\section{Results}

1. Comparison of the muscle activity analysis according to the obstacle width

The muscle activities of the VL and soleus of the lead leg and stance leg after crossing the obstacle and the muscle activity of the soleus of the lead leg increased significantly with increasing obstacle width $(\mathrm{p}<.05)$. In other cases, the muscle activities increased with increasing obstacle width, but the difference was not significant $(\mathrm{p}>.05)$ (Table 2). 
Table 3. Comparison of the Muscle Activity According to the Obstacle Height with a $7 \mathrm{~cm}$ Width (Median Value)

\begin{tabular}{|c|c|c|c|c|c|}
\hline \multirow{2}{*}{ Event } & \multirow{2}{*}{ Muscle } & \multicolumn{3}{|c|}{ Height of Obstacle } & \multirow{2}{*}{$\mathrm{p}$} \\
\hline & & $0 \%$ & $10 \%$ & $40 \%$ & \\
\hline \multirow{4}{*}{ Stance Leg } & $\mathrm{VM}$ & $15.03^{\mathrm{b}}$ & $21.43^{\mathrm{c}}$ & $32.53^{\mathrm{b}, \mathrm{c}}$ & $.001^{*}$ \\
\hline & VL & $13.87^{\mathrm{a}, \mathrm{b}}$ & $22.07^{\mathrm{a}, \mathrm{c}}$ & $33.07^{\mathrm{b}, \mathrm{c}}$ & $.004^{*}$ \\
\hline & $\mathrm{TA}$ & $14.93^{\mathrm{b}}$ & $22.27^{\mathrm{c}}$ & $31.80^{\mathrm{b}, \mathrm{c}}$ & $.002^{*}$ \\
\hline & Soleus & $13.87^{a . b}$ & $22.07^{\mathrm{a}, \mathrm{c}}$ & $33.07^{\mathrm{b}, \mathrm{c}}$ & $.000^{*}$ \\
\hline \multirow{4}{*}{ Lead Leg } & $\mathrm{VM}$ & $8.97^{\mathrm{a}, \mathrm{b}}$ & $25.10^{\mathrm{a}, \mathrm{c}}$ & $34.93^{\mathrm{b}, \mathrm{c}}$ & $.000^{*}$ \\
\hline & VL & $15.20^{\mathrm{b}}$ & $22.67^{\mathrm{c}}$ & $31.13^{\mathrm{b}, \mathrm{c}}$ & $.000^{*}$ \\
\hline & $\mathrm{TA}$ & $13.47^{\mathrm{b}}$ & $21.27^{\mathrm{c}}$ & $34.27^{\mathrm{b}, \mathrm{c}}$ & $.000^{*}$ \\
\hline & Soleus & $15.20^{\mathrm{b}}$ & $22.67^{\mathrm{c}}$ & $31.13^{\mathrm{b}, \mathrm{c}}$ & $.004^{*}$ \\
\hline \multirow{4}{*}{$\begin{array}{c}\text { Stance Leg After Crossing } \\
\text { Over Obstacle }\end{array}$} & $\mathrm{VM}$ & $11.50^{\mathrm{a}, \mathrm{b}}$ & $24.63^{\mathrm{a}}$ & $32.87^{\mathrm{b}}$ & $.000^{*}$ \\
\hline & VL & $12.13^{\mathrm{a}, \mathrm{b}}$ & $23.27^{\mathrm{a}, \mathrm{c}}$ & $33.60^{\mathrm{b}, \mathrm{c}}$ & $.000^{*}$ \\
\hline & $\mathrm{TA}$ & 20.33 & 23.13 & 25.53 & .555 \\
\hline & Soleus & $12.13^{\mathrm{a}, \mathrm{b}}$ & $23.27^{\mathrm{a}, \mathrm{c}}$ & $33.60^{\mathrm{b}, \mathrm{c}}$ & $.000^{*}$ \\
\hline \multirow{4}{*}{ Trailing Leg } & $\mathrm{VM}$ & $11.97^{\mathrm{a}, \mathrm{b}}$ & $24.30^{\mathrm{a}, \mathrm{c}}$ & $32.73^{\mathrm{b}, \mathrm{c}}$ & $.000^{*}$ \\
\hline & VL & $10.80^{\mathrm{a}, \mathrm{b}}$ & $24.07^{\mathrm{a}, \mathrm{c}}$ & $34.13^{\mathrm{b}, \mathrm{c}}$ & $.000^{*}$ \\
\hline & $\mathrm{TA}$ & $16.33^{\mathrm{b}}$ & 23.13 & $29.5^{\mathrm{b}}$ & $.023^{*}$ \\
\hline & Soleus & $14.40^{\mathrm{b}}$ & $20.47^{\mathrm{c}}$ & $34.13^{\mathrm{b}, \mathrm{c}}$ & $.000^{*}$ \\
\hline
\end{tabular}

VM: Vastus Medialis, VL: Vastus Lateralis, TA: Tibialis Anterior

${ }^{*} \mathrm{P}<.05$,

a,b,c: Post hoc analysis with Bonferroni's method $(\mathrm{p}<.017)$

\section{Comparison of the muscle activity according} to the obstacle height with a $7 \mathrm{~cm}$ width

The muscle activities increased significantly with increasing obstacle height, except for the muscle activity of the TA of the stance leg after crossing over the obstacle $(\mathrm{p}<.05)$. Table 3 lists the result of the post-hoc test.

\section{Comparison of the muscle activity according} to the obstacle height with a $14 \mathrm{~cm}$ width

The muscle activity increased significantly with increasing obstacle height, except for the muscle activity of the VL, soleus of the leading leg, and TA of the stance $\operatorname{leg}(p<.05)$. Table 4 lists the result of the post-hoc test.

\section{Discussion}

This study examined the muscle activity of the lower extremity while walking over obstacles according to the height and width of the obstacles. The muscle activities of the VL and soleus of the stance leg and lead leg after crossing over obstacles increased with increasing obstacle width. The muscle activities of the lower extremity increased with increasing obstacle height.

The soleus muscle plays a very important role in controlling the advance of the tibia on the talus at the ankle joint [9]. The advance of the tibia of the lead leg and stance leg after crossing over an obstacle was controlled more by the soleus as the obstacle width increased.

The quadriceps femoris muscle is the largest and most 
Table 4. Comparison of the Muscle Sctivity According to the Dbstacle Height with a $14 \mathrm{~cm}$ Width

\begin{tabular}{|c|c|c|c|c|c|}
\hline \multirow{2}{*}{ Event } & \multirow{2}{*}{ Muscle } & \multicolumn{3}{|c|}{ Height of obstacle } & \multirow{2}{*}{$\mathrm{p}$} \\
\hline & & $0 \%$ & $10 \%$ & $40 \%$ & \\
\hline \multirow{4}{*}{ Stance Leg } & $\mathrm{VM}$ & $15.53^{\mathrm{b}}$ & $20.07^{\mathrm{c}}$ & $33.40^{\text {b.c }}$ & $.001^{*}$ \\
\hline & VL & $13.73^{\mathrm{b}}$ & $22.20^{\mathrm{c}}$ & $33.07^{\mathrm{b}, \mathrm{c}}$ & $.000^{*}$ \\
\hline & $\mathrm{TA}$ & 18.27 & 21.33 & 29.40 & .056 \\
\hline & Soleus & $13.73^{\mathrm{b}}$ & $22.20^{\mathrm{c}}$ & $33.07^{\mathrm{b}, \mathrm{c}}$ & $.000 *$ \\
\hline \multirow{4}{*}{ Lead Leg } & $\mathrm{VM}$ & $10.40^{\mathrm{a}, \mathrm{b}}$ & $25.07^{\mathrm{a}}$ & $33.53^{b}$ & $.000 *$ \\
\hline & VL & 18.40 & 21.20 & 29.40 & .058 \\
\hline & $\mathrm{TA}$ & $11.60^{\mathrm{a}, \mathrm{b}}$ & $24.27^{\mathrm{a}}$ & $33.13^{\mathrm{b}}$ & $.000^{*}$ \\
\hline & Soleus & 18.40 & 21.20 & 29.40 & .058 \\
\hline \multirow{4}{*}{$\begin{array}{c}\text { Stance Leg After Crossing } \\
\text { Over Obstacle }\end{array}$} & $\mathrm{VM}$ & $12.53^{b}$ & 23.00 & $33.47^{b}$ & $.000^{*}$ \\
\hline & VL & $18.33^{\mathrm{b}}$ & $18.20^{\mathrm{c}}$ & $32.47^{\mathrm{b}, \mathrm{c}}$ & $.003^{*}$ \\
\hline & $\mathrm{TA}$ & $16.53^{\mathrm{b}}$ & 22.07 & $30.40^{\mathrm{b}}$ & $.014^{*}$ \\
\hline & Soleus & $18.33^{\mathrm{b}}$ & $18.20^{\mathrm{c}}$ & $32.47^{\mathrm{b}, \mathrm{c}}$ & $.003^{*}$ \\
\hline \multirow{4}{*}{ Trailing Leg } & VM & $15.53^{\mathrm{b}}$ & $20.47^{\mathrm{c}}$ & $33.00^{\mathrm{b}, \mathrm{c}}$ & $.001^{*}$ \\
\hline & VL & $11.53^{\mathrm{a}, \mathrm{b}}$ & $22.73^{\mathrm{a}, \mathrm{c}}$ & $34.73^{\mathrm{b}, \mathrm{c}}$ & $.000^{*}$ \\
\hline & $\mathrm{TA}$ & $17.40^{\mathrm{b}}$ & 21.67 & $21.67^{b}$ & $.029^{*}$ \\
\hline & Soleus & $12.33^{\mathrm{a}, \mathrm{b}}$ & $24.47^{\mathrm{a}}$ & $32.20^{\mathrm{b}}$ & $.000^{*}$ \\
\hline
\end{tabular}

VM: Vastus Medialis, VL: Vastus Lateralis, TA: Tibialis Anterior

${ }^{*} \mathrm{P}<.05$, a,b,c: Post hoc analysis with Bonferroni's method $(\mathrm{p}<.017)$

powerful muscle in the body. This muscle is responsible for maintaining the normal position of the knee and absorbing the shock of the initial contact in gait $[9,10]$. The VM and VL work together to stabilize the knee during heel off $[9,11,12]$. In this study, the muscle activity of the VL increased with increasing height and width of the obstacles. The reason for the increased muscle activity of the VL may be the demand for stabilizing the knee. Therefore, training of the VL is needed first to cross over obstacles safely.

Chung et al. [13] reported no significant difference in the muscle activity of TA in the elderly, even if the obstacle height increased. Sparrow et al. [14] reported no significant difference in the foot clearance of the lead leg but a significant difference in the trail leg according to the obstacle height.
In this study, the muscle activity of TA increased with increasing obstacle height. This may be due to the difference in the height of the obstacles and the age of the subjects. The obstacles used in this study were higher, and the subjects were younger than in Chung et al.'s study [13].

Similarly, Park et al. [5] reported that the muscle activity of the TA of the stance leg increased with increasing obstacle height. The characteristics of the participants were the same, and the age of the participants was 20 years in both studies.

Cho [15] found that the muscle activity of the TA, soleus, and quadriceps in the elderly were higher when crossing over obstacles than with normal walking. He suggested that more muscle power was used for stabilizing while traversing obstacles. In this study, the muscle activities 
increased while crossing over a $10 \%$ obstacle height than a $0 \%$ obstacle height.

As the height of the obstacle increased, the time for moving the center of pressure increased significantly in the stance phase [16], and the center of pressure moved slowly [17]. Similarly, this study found that the muscle activities increased as a compensatory strategy to lift the swing leg. In other words, increasing the traveling time of the center of pressure requires more muscle activities to cross over the obstacle. Greater propulsion is needed to cross over obstacles, which requires more stability and muscle activities of the stance leg and lead leg.

In this study, the role of the soleus and VL increased with increasing obstacle width. Therefore, it is necessary to strengthen these muscles to prevent falls that may occur while crossing over obstacles, such as passing over subway platforms. To traverse a doorsill or bathtub, strength and coordination of the lower extremities are necessary. Accordingly, it is necessary to strengthen the entire lower extremity.

Older adults stumble on obstacles and fall more often than younger adults, and have an increased risk of injury [18]. The standard data can also be applied to prevent falls for older adults.

The age and number of participants were restricted because of a pilot study. Therefore, there is a limitation in the generation of the results of this study. In this study, a single task during gait was tested, not a dual-task, which limits the application to everyday life. In addition, the other factors, such as the ground reaction force, were not evaluated, and only the muscle activity was assessed. Hence, there is some limitation when interpreting the results of stepping over an obstacle.

\section{Conclusion}

This study examined the muscle activity of the lower limbs while crossing over obstacles, which may be the cause of falls, according to change in the height and width of the obstacle. As the width of the obstacle increased, the role of VL and soleus increased, and the overall muscle activities of the lower extremities increased with increasing obstacle height. Overall, a program for preventing falls can be developed based on these results.

\section{Acknowledgments}

This work was supported by the National Research Foundation of Korea(NRF) grant funded by the Korea government(MSIT) (No. NRF-2018R1D1A1B07047562)

\section{References}

[1] Chen HC, Ashton-Miller JA, Alexander NB, et al. Stepping Over Obstacles: Gait Patterns of Healthy Young and Old Adults. J Geriatr. 1991;46(6):196-203.

[2] Lee JE, Lee HS. Effects of Treadmill Gait Training with Obstacle-Crossing on Static and Dynamic Balance Ability in Patients with Post Stroke Hemiplegia. J Korean Soc Phys Med. 2019;14(1):139-50

[3] Kim HK, Song YG, Kim YH, et al. Avoidance Strategies of Multiple Obstacles in Patients with Cerebellar Disease. KJSP. 2012;23(1):1-14.

[4] Krell J, Patla AE. The influence of multiple obstacles in the travel path on avoidance strategy. Gait Posture. 2002;16(1):15-9.

[5] Park JS. Kinetic Analysis of the Gait of the Lower Limbs of Women in their 20's when Crossing Obstacles According to Various Heel and Obstacle Heights. Master's Degree. Kyung Sung University. 2015.

[6] Kim HY, Kim YH, Song YG, et al. Characteristics of Obstacle Crossings with Different Heights in Patients with Cerebellar Disease. KJSP. 2011;22(3):87-98.

[7] Houser J, Decker L, Stergiou N. Stepping over obstacles of different heights and varied shoe traction alter the kinetic strategies of the leading limb. Ergonomics. 
2008;51:1847-59.

[8] Criswell, Eleanor C, Jeffrey R. Cram's introduction to surface electromyography, 2nd ed. Massachusetts. Jones and Bartlett. 2011.

[9] Janet MA, Kay C. Observational gait analysis: A visual guide, 1st ed. Thorofare, NJ. Slack Inc. 2018.

[10] Jang JH, Kim KH, Kim TH, et al. The Effects of Foot and Knee Position on Electromyographic Activity of the Vastus Medialis and Vastus Lateralis for Hemiplegic Patients. J Kor Soc Phys Ther. 2010;22(4):21-8.

[11] Heegaard J, Leyvraz PF, Van Kampen A, et al. Influence of soft structures on patellar three-dimensional tracking. Clin Orthop Relat Res. 1994;299:235-43.

[12] Park S. Biomechanical analysis of the quadriceps femoris according to the knee alignment in young adults. Doctor's Degree. Catholic university in Dae gu. 2013.

[13] Chung CS, Yoon TJ, Yu YJ, et al. Analysis of kinematics and EMG on stepping over obstacles in elderly persons.
The Korean Journal of Physical Education. 2004;43(5): 423-36.

[14] Sparrow WA, Shinkfield AJ, Chow S, et al. Characteristics of gait in stepping over obstacles. Hum Mov Sci. 1996;15(4):605-22.

[15] Cho YH. Analysis of Gait Velocity, Lower Muscles Activity on Obstacle and Dual Task Gait in Elderly Women. J Korean Soc Phys Med. 2011;6(4):465-73.

[16] Park S, Kim K, Park JW. Time Difference of the COP Displacement according Obstacle Height during Obstacle Crossing in Older Adults. J Kor Phys Ther.2011; 23(2):1-5.

[17] Wang Y, Watanabe K. The relationship between obstacle height and center of pressure velocity during obstacle crossing. Gait Posture. 2008;27(1):172-5.

[18] Galna B, Peters A, Murphy AT, et al. Obstacle crossing deficits in older adults: a systematic review. Gait Posture. 2009;30(3):270-5. 